ANTIFRAGILITY, STABLE ADAPTATION

AND FUTURE-PROOFING: REDEFINING THE SPIRIT AND PURPOSE OF REGIONAL DEVELOPMENT STRATEGY IN AUSTRALIA'S PERIPHERAL REGIONS

\title{
Tony SORENSEN
}

University of New England

Armidale, NSW 2351, Australia

Tony.Sorensen@une.edu.au

\begin{abstract}
Australia's rural regions typically have fragile and narrow economic bases specializing in agriculture, mining, or leisure and recreation. We canvass the major sources of economic fragility, which is growing fast through global competition, massive technological progress, and many other pressures for change. These severely diminish the capacity of governments to deliver effective top-down and one-size-fits-all regional development strategies. The antidote to fragility resides instead in local self-help strategies designed to increase communities' entrepreneurial, technological, future-oriented, and innovative capacities. Knowledge about optimal delivery of such outcomes in Australia's sparsely settled regions is, however, limited. This suggests an agenda of action research to promote and document local experiences - both successes and failures - in promoting the cultural change necessary to deliver stable adaptation.
\end{abstract}

Key-words: antifragility, rural Australia, regional development strategy, local self-help, cultural change, stable adaptation

\begin{abstract}
"Change before you have to; face reality as it is, not as you wish it to be; control your own destiny or someone else will; if you don't have competitive advantage don't compete; and if the rate of change on the outside exceeds the rate of change on the inside, the end is near."
\end{abstract}

Selected quotes from Jack Welch, former CEO of General Electric

\section{Introduction}

Australia's rural economies are, in Taleb's (2012) terms, particularly fragile for reasons we will explore. Fears and expectations engendered by this fragility have in turn underpinned a raft of traditional regional development strategies orchestrated mainly by federal and state governments over the last half century. Such top-down strategies have typically focused on infrastructure provision, hunting and relocating new industries, or attempting to grow new industries in situ. Yet all the evidence points to the relative failure of such approaches, and it is arguable that the economic and social trajectories of most regions 
differ little from what would have occurred in the absence of policy (Sorensen 2000, 2002). Another focus is therefore to explain this lack of policy impact and, moreover, we shall see that many the causes are becoming more entrenched and intractable. In the light of governments' increasing incapacity to assist specific regions (Sorensen 2002), our attention finally turns towards a slate of possible actions designed to deliver adaptive regional business cultures. These have to be capable of seizing an avalanche of new opportunities raised by burgeoning technologies, fast economic growth in the Pacific region, and economic globalization more widely. This also opens up an enormous future research agenda exploring avenues for regional self-help. But, given the enormous differences in regional resources, infrastructures, and geographical accessibility, optimal strategies are likely to differ greatly in detail from one place to another. As a sub-plot, we also focus on a development environment in many respects far removed from European experience. Australia's relatively open and market-oriented economy located in a somewhat hostile geographical environment promises to become a proving ground for new ideas about steering the development of place and space.

\section{On Regional Fragility}

This analysis focuses mainly on regions classified by the Australian Bureau of statistics (ABS) as Outer Regional, Remote and Very Remote, which we will term ORRVRA. Figure 1 shows their spatial distribution across most of the continent, which is roughly the same size as the United States south of the 49th parallel. ORRVRA typically lies $100 \mathrm{~km}$ or more beyond Australia's major urban conurbations and offers few opportunities for daily commuting. Thus their economies are largely dominated by primary industries or leisure and recreation. In the case of the author's home region, New England and the North-west of NSW, $16.3 \%$ of workers were either in agriculture or mining in 2011. Moreover, ORRVRA's populations are sparse, comprising a little over 2.5 million people, or about $11.4 \%$ of Australia's total population of 22.3 million in 2011. Some 2 million people live in Outer Regional Australia, the nation's agricultural heartland, while locations classified as remote are home to just 500,000 inhabitants. To make matters worse, Figure 2 shows that the numbers of people living in many parts of ORRVRA are in decline or at best static. The main exceptions are the booming mineral provinces of northern Australia, which are experiencing one the greatest expansions in human history, and several benign coastal locations.

Sparse and declining populations make it increasingly expensive to provide adequate social and infrastructure services and agricultural, or even mineral, monocultures make for exceedingly narrow economic bases. Throw in oppressive climates where temperatures frequently exceed $40 \mathrm{C}$, and there are few incentives for people to remain in many rural locations once they retire or become unemployed. They are often low amenity locations (Argent et al. 2013). But fragility has many other much larger and interacting dimensions. For example, rural economies are at the mercy of both fluctuating commodity prices and highly variable seasonal conditions. The value of the Australian dollar is also crucial for both farm and mine incomes. Most prices for agricultural commodities are set via the Chicago Mercantile Exchange and quoted in \$US. The London Metal Exchange similarly prices many minerals in $f$ sterling. After the start of the global financial crisis in 2007-2008, the value of the A\$ rose from about US\$0.6 to > US\$1.0 because Austra- 


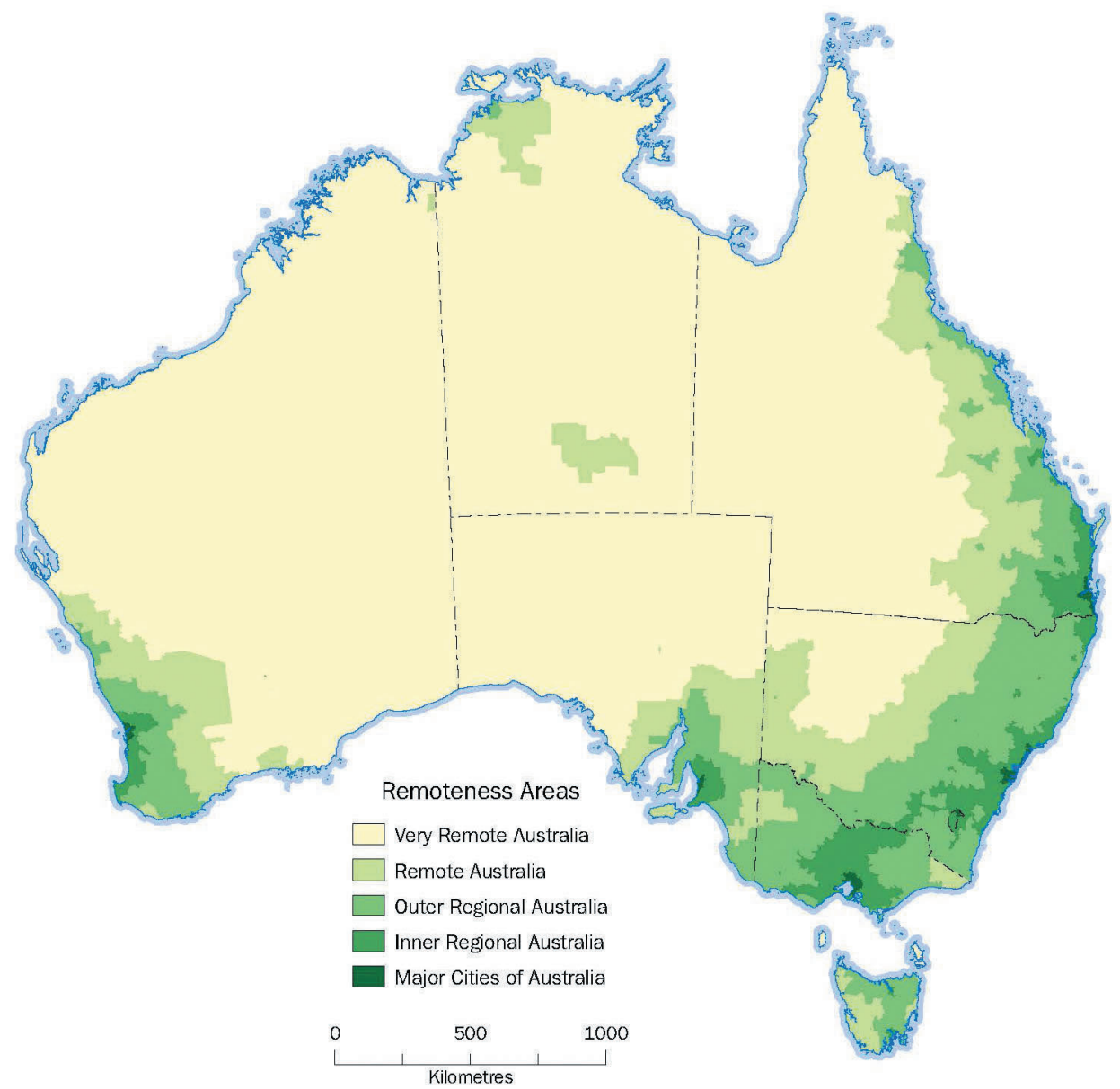

Fig. 1. Australian Bureau of Statistics Remoteness Areas 2011

Source:http://www.ausstats.abs.gov.au/Ausstats/subscriber.nsf/0/2B9F179C6CFA2431CA257B03000D7F21/\$File/1270055005_2011_remoteness_structure_maps.pdf

lia experienced no recession; was running budgetary surpluses; offered high interest on bank deposits; saw rising demand for, and prices of, mineral and agricultural commodities from China and other Asian economies; and attracted large inflows of foreign investment capital. Since Australia exports two-thirds of its agriculture output and nearly all its mineral production, the rising value of the dollar nominally slashed producer incomes by up to $60 \%$. In practice, the losses were less because of rising commodity prices and lower input costs arising from cheaper imports. On the down-side, some agricultural production suffered from rising import competition from lower cost countries - including citrus fruit and pork products. Fluctuating metal and energy prices also sometimes result in the sudden opening or closure of mines, the antidote to which is the development of fly-in / fly-out (FIFO) and drive-in / drive-out (DIDO) cultures (Storey 2001). The resulting economies are almost purely extractive. Once resources are exhausted, all that remains is a hole in the ground and maybe ghost infrastructure. 


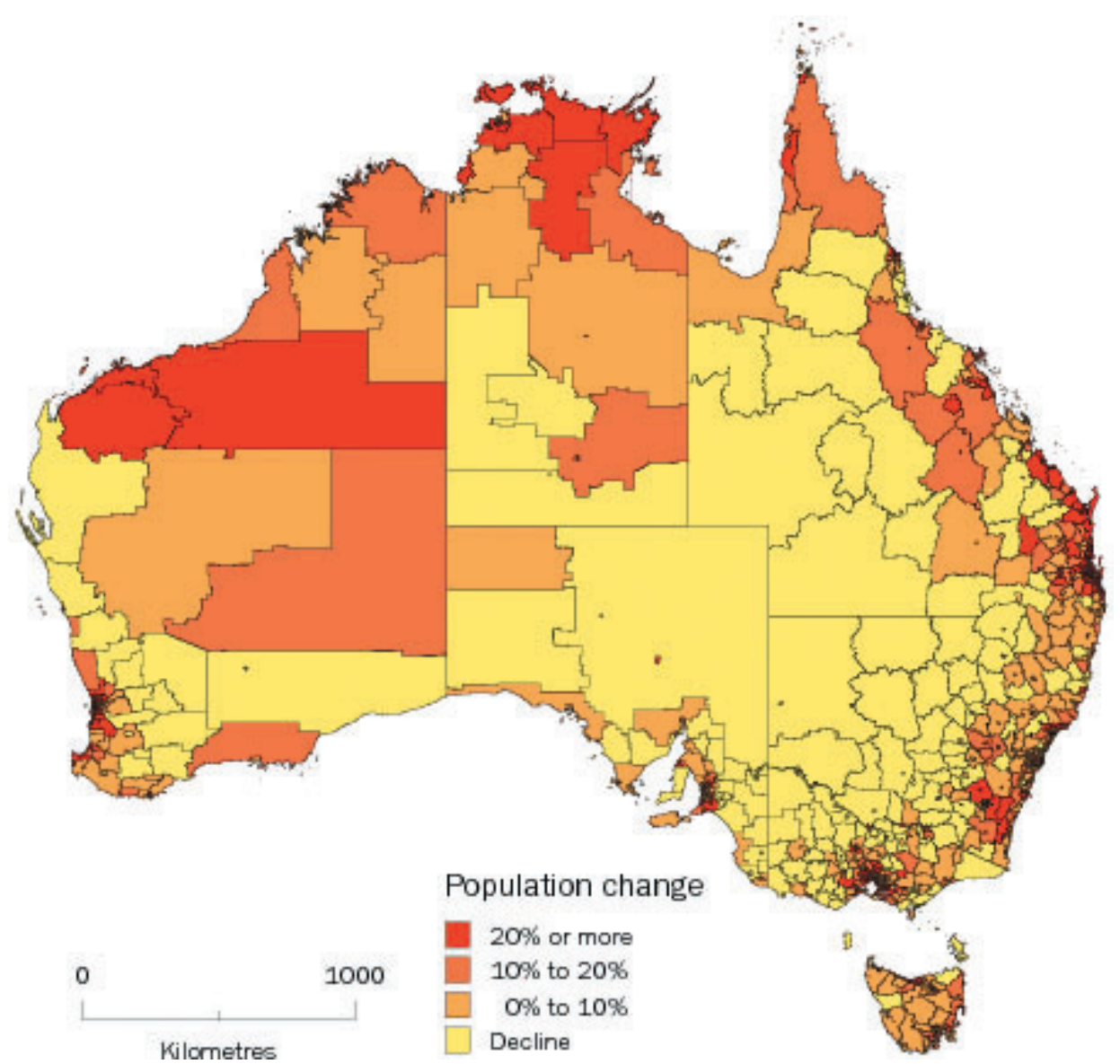

Fig. 2. Australia: Local Government Areas Population Change 2001-2011

Source: http://www.abs.gov.au/ausstats/abs@.nsf/Products/3218.0 2011 Main+Features Main+Features?Op enDocument\#PARALINKO

All these instabilities are, in turn, magnified by massive economic uncertainty of the kinds identified by Taleb (2007) and Sorensen (2009b, 2011b). At a theoretical level, these involve:

1. Economic and social complexity (multitudes of intersecting variables with extensive feedback loops), all made worse by globalization and rapid shifts in spatial patterns of production resulting from dynamic changes of comparative and competitive advantages among nations and regions.

2. Huge information deficiencies about variables and their impacts - in a fast moving and complex world, the information at our disposal is patchy and soon dated.

3. Extreme leveraging of both economic growth and decline in the spirit of chaos theory - witness (a) the growth of the BRIC nations or the collapse of some American cities like Detroit or (b) the sudden collapse of governments.

4. The existence of environmental tipping points, typically leading to the sudden collapse of some agricultural and resource industries. 
5. Asynchronous cycles (analogous with quantum mechanics) most economic processes take wave forms such as the business, product, technology, and fashion life-cycles. The chance intersection of these wave cycles across industries and nations as a whole poses nightmares for governors of reserve banks. They have grudgingly acknowledged two speed economies, but the reality might be closer to eight or ten.

6. The prevalence of such destabilizing psychologies like fear \& greed, well described by Prechter's (2003) socionomics.

7. Prevalent non-linearities between cause and effect between nearly all system variables (Taleb 2007, 2012).

Table 1. 14 Technology Arenas Likely to Transform Rural Australia's Base Industries: crops / livestock / fisheries / mining \& energy / forestry / tourism / retirement

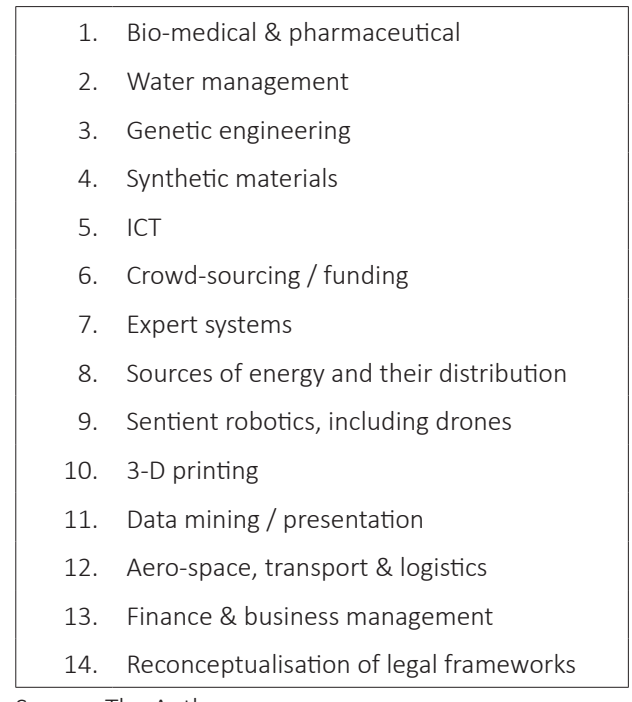

Source: The Author

To these we might add large-scale corporate malfeasance and/or incompetence, and government mismanagement, which combined to kick-start the current global financial crisis (GFC). Perhaps we should also toss in the corruption of international trade by large producer subsidies or various forms of trade barrier. We're not finished yet, for on the up-side we have a large range of burgeoning technologies (see Table 1) set to transform the economic world in terms of goods and services produced, jobs performed and skills needed, resources and other inputs, the organization of business and financial management, and transport logistics (Brynjolfsson and McAfee 2014; Hammersley 2012). Such authors also note (a) the dramatic decline in the lapse time between pure research and development of commercial products, (b) the ever faster adaptation of existing products to new \& unimagined uses, and (c) the rising power of integrating multiple technologies. For example, every supplier of regional producer and consumer services in Australia is potentially threatened with redundancy by e-commerce / e-networking and associated lifestyle changes.

In summary, all these processes are in the process of dramatically changing what is produced where, and by implication where people will live and migrate. Moreover, they 
appear largely uncontrollable, especially by regional and national governments which are increasingly subservient to an ultra-competitive multi-polar world order (World Bank 2011). In such an environment, policy is increasingly focusing on forms of macro-economic management designed to create investment friendly financial stability mediated through such intersecting agencies as national reserve banks and prudential regulators and their global counterparts. And governments are increasingly constrained by what one might term a democratic deficit. Simply put the task of having to win elections and retain office against a background of endemic social fragmentation is likely to impede seriously the task of effective policy formation and management. A British study (Savage et al. 2013) reported the existence of seven 'social classes' in that country, not the two or three presumed for most of the 20th century, each determined to defend its perceived interests which rarely have anything to do with adjusting to the inevitable economic realities of the coming world order. In short, most future governments are likely to represent unstable coalitions of interests in which policy deliberations will be time consuming at the precise time that fast action is demanded. Moreover, their resulting policies are likely to be belated and second-best compromises. All the uncertainties documented here suggest that governments now have little or no capacity to steer regional destinies (Sorensen 2000, 2002). Put another way, such incapacity imparts further fragility to Australia's rural regions at the very time they confront an avalanche of new technologies and global competition in an environment where accurate spatial forecasting is nigh-on impossible.

Such fragility has important consequences. Australia's settlement system was completed about 100 years ago, but many small villages have subsequently disappeared and even larger settlements, whose populations lie in the 2,000 to 20,000 range, often struggle to survive. In a heavily market-oriented economy, where agriculture is subsidized only to about $5 \%$ of the gross value of production compared with much higher numbers for the US, Europe, and East Asia, farm consolidation has eliminated many small-scale producers and the number of people describing their occupation as farmers is fast collapsing despite strongly rising output. Note also that the forms and extent of fragility will vary spatially and temporally according to such dimensions as the extent and quality of local resources, the extent of global competition, domestic rather than export orientation, local economic diversity, population size and density, and geographical accessibility.

\section{Antidotes to Atrophy and Attrition}

Fragility unsurprisingly begets fear among rural populations that their regional lifestyles, wellbeing, and prospects are threatened. For the last 50 years, both state and federal governments in Australia have experimented with disconnected and often sporadic strategies designed to increase regional populations, diversify economic bases, improve production technologies, raise average incomes, and provide residents and businesses with good quality infrastructure and public services. Evidence suggests that the first two of these goals have failed miserably. The population statistics reported above testify to the declining share of national population in rural regions as a whole and the growth of population in mining provinces reflects mineral discovery and exploitation by corporations rather than government endeavor. Strategies for diversification into manufacturing and higher order services also fell afoul of the nation-wide slaughter of manufacturing jobs 
by engagement with much cheaper Asian based suppliers, first in Japan, then Korea, and subsequently China, India, Bangladesh and elsewhere. In 1970, the national proportion of workers in manufacturing was 30\%, a figure now down to a little over $7 \%$. Several of these themes are addressed by Sorensen (2002) and The Regional Australia Institute (2012) ${ }^{1}$.

On the other hand, improvements to infrastructure and services had little to do with formal regional strategies. Those outcomes rested on community services obligations (CSOs) executed by line departments charged with delivering transport, education and health, not formal regional strategy. Extensive government funding of research and development for primary industries also contributed greatly to rising total factor productivity growth and farm incomes, but accelerated farm consolidation and the loss of workers in the industry and their families (Productivity Commission 2005; Sorensen 2009a). Regional development strategies are still in place because rural electorates expect as much, but their share of government funding and of regional economies is derisory and, until recently, governance structures were complex and uncertain (Sorensen et al. 2007).

The issue then becomes: what then can we do to boost regional economic diversity and wealth? In a market economy - and Australia ranks third on the Heritage Foundation's index of global economic freedom ${ }^{2}$ - the recipe seems to be nothing short of replicating as closely as possible two interlocking cultures: (1) Taleb's (2012) notion of optionality and (2) the entrepreneurial and innovative culture of Silicon Valley ${ }^{3}$. In many respects, this agenda is psychological, as anticipated by Sorensen (2009b, 2010). And, as we will show, this cultural transformation is largely in the hands of local and regional communities' residents, not state and federal government, whose primary roles in both cultures lie much more in providing a stable and investment focused economy while meeting essential CSOs. In a decentralized market economy, this recipe is unlikely to be achievable universally, leaving behind many places unable to muster the necessary resources for their improved well-being or even survival. However, this outcome appears equally likely under both government and market scenarios.

Taleb devised optionality as a key survival and adaptive strategy for SMEs in rapidly changing and highly competitive world. In Australia's rural contexts it seems to apply equally for farmers (who often run SMEs), local service enterprises, community organizations, and local governments - indeed the whole of rural economy and society. In my view, the creation of robust communities is a whole-of community endeavor leading to stable adaptation (Sorensen and Epps 2005) in the sense of keeping up with and responding quickly to the forces of change. Indeed, optionality also works for individuals and this author uses it in running a superannuation fund just as the strategy worked for Taleb when he was a Wall Street trader.

Optionality requires all relevant actors in rural communities, both individually and collectively to:

1. Constantly comb their domains for future options arising from emerging and evoIving technologies (or possibly fashions) and/or their adaptation to new uses.

1 See http://www.regionalaustralia.org.au/wp-content/uploads/2013/07/RAI-Stocktake-of-RegionalResearch-50-pieces-of-influential-research.pdf for the Regional Australia Institute's stocktake of regional research including the capacity of government policy to transform regions and the drivers of regional change.

2 See http://www.heritage.org/index/

3 Ably documented by in a Startup Genome Report in 2011, which can be sourced at: http://gallery.mailchimp.com/8c534f3b5ad611c0ff8aeccd5/files/Startup_Genome_Report.pdf. This organisation also ranks the innovatory capacity of the world's leading technology nodes. 
2. Evaluate those options as far as possible in quantitative and qualitative terms for:

a. Their impact, good or bad, on current commodities, goods or services provided

b. Alternative remedial strategies, if any, to cement in place those current activities by tweaking volume and quality of operations, or methods of delivery

c. New commodities, goods or services, whether emergent from current operations or completely new

d. Prospects for, and extent of, first mover advantage arising from (b) and (c).

3. Select those options with some optimal combination of:
a. Lowest risk
b. Highest ratio of upside to downside
c. Greatest long-term pay-off
d. Exponentially upward expanding possibilities
e. Highest benefit to cost ratio.

Their congruence with current culture, preferences, and actions is of minor importance. Moreover, a rapidly changing and complex world may offer few and somewhat disconnected clues for the necessary calculations. This is why Taleb (2012) talks about having "skin in the game", which elsewhere both he and I call experience. Unsurprisingly, we share the same guru, the philosopher Montaigne (1580), who advocates experience as the best guide to life.

4. Be prepared to take calculated risks. Don't be afraid of mistakes! Silicon Valley's initial start-up failure rate is anecdotally c. 75-85\%, depending on (I) measurement techniques and (II) their timing. However, for those trying a second time the failure rate is only $70 \%$. The benefit of the successes is truly spectacular and buries the losses of all the failures. In a complex and rapidly changing economic and social environment, present practice may offer the decision-maker little of value. So do not dwell in the past!

So at the heart of optionality is the detection of a constant stream of ideas relating to goods and services and/or their production, wise choice among alternatives, finding the entrepreneurs and venture capital to implement those choices and, in Taleb's view, financial conservatism within businesses and society's institutions - retaining capital for both a 'rainy day' when one's business or organization encounters turbulent conditions or for great opportunities that swim into view. For these reasons he dislikes the debt culture of the 2000s which led directly to the GFC. These actions are going to be highly fluid and the actors in the game require continuously imaginative mind-sets, which neatly brings us to the ultra-innovation of the world's technological hubs, like Silicon Valley. According to startup genome, such places typically meld the following attributes. They are information rich, heavily networked, future oriented, highly imaginative, intensely entrepreneurial, mentally flexible, accessible to large pools of venture capital, institutionally rich, mutually supportive, and willing to discard the past or unsuccessful initiatives. In Stanislav Lem's (2013) view, "analysis must be abandoned in favour of creative activity - of imitological practice. Hard-won objectivity drowns in a glut of complexity. So humans must grow into the fabric of the world", a diagnosis that agrees with Taleb's "having skin in the game".

This agenda must be heavily local for a myriad of reasons. A whole of society task is difficult to achieve at the level of the nation state with all its competing interests and perspectives. 
Local communities, on the other hand, can often be galvanized by strong leadership, especially where a collection of local institutions act together through constructive dialogue - though not necessarily with singularity of view. In contrast, national and provincial governments tend to have little idea about local options or community aspirations in highly diversified rural space. Nor can they respond rapidly to changing or fast moving scenarios because of the ponderous processes of democracy discussed previously. FinalIy public bureaucracy tends to prefer useless one size-fits-all policies over flexibility and the sheer spatial diversity of rural life demands bespoke solutions (Sorensen 2009c). The logical outcome of this analysis is also daunting. Local and regional development, especially in remoter communities cannot be is about preserving existing lifestyles, cultures and industries ... or sometimes even environments. Nor is it about developing broad-based blue-prints for the controlled evolution of future rural space, either by central governments, local authorities, or communities themselves. These agendas appear dead in times of turmoil, instability and uncertainty, which is where Jack Welch's initial dictums come into play. The only game in town is to invent the future, but do it at least as fast as the future arrives so that we inhabit regional communities enjoying stable adaptation. If we accept the notion embodied in Moore's Law, and extolled by the likes of Brynjolfsson and McAfee (2014), Hammersley (2012), Lem (2013) or Stephenson et al. (2013) that the future is accelerating exponentially and in often strange ways, participants in local and regional development may need exponentially flexible mind-sets, ever greater preparedness to accept risk and willingness to contest the past, faster ability to debate alternative perspectives, and frantic experimentation with new styles of entrepreneurial behavior. All this is, of course, not without risk as Brockman (2014) and his colleagues point out in entertaining but also alarming fashion. Rapid change is likely to engender all manner of unpleasant, unintended and probably unavoidable outcomes. Both Brynjolfsson and McAfee and Stephenson et al. adopt a similar lines albeit it with vastly different styles.

\section{A New Research Agenda?}

Can we, in effect, impart the values and capabilities of Silicon Valley in small-scale regional societies characterized by:

- Low population density

- Disconnected communities often separated by $100 \mathrm{~km}$ or more

- Conservative respect for tradition

- Mobile workforces

- The prevalence of SMEs, rather than large corporations

- Fragile industries buffeted by flood, fire, drought, and oscillating commodity prices?

We in Australia, unlike most other parts of the world, have some track record in thinking how it might be done effectively and efficiently. Here, at least, the two dominant primary industries - agriculture and mining - already share many of the innovative characteristics of the world's leading innovation hubs and, over many years agriculture has recorded Australia's highest total factor productivity growth - much higher even than ICT (Productivity Commission 2005). The reason is very simple. If farmers have amongst the lowest government support of any in the world and they have to export two-thirds of their produce into corrupted global markets, the only way they can compete effecti- 
vely is to embrace quickly the latest research and development, embrace new varieties of crops and livestock, raise the quality of output, reduce costs through scale economies and mechanization, and bring output quicker to market (Sorensen 2011a). In short, most successful farmers employ expediently many of the technological arenas listed in Table 1. Moreover and Deloitte (2014) nominates agribusiness as a principal harbinger of Australia's future prosperity and locus of greatest comparative advantage alongside the minerals and energy (mining, gas and oil), tourism, international education and wealth management. In short, rural basic industries top the list of growth sectors - unlike most countries on this planet.

For rural Australia, however, the development problem tends to lie with the provision of producer and consumer services and the slow recognition and take-up of new opportunities being released from the shackles of geography by ICT in particular, but also new forms of energy. In effect, rural regions host a two-speed economy, though to be fair both mining and agriculture could also benefit from a greater impetus for change to deliver greater efficiency and effectiveness. These observations suggest, in turn, the kind of research agenda set out in Table 2. Most of the themes listed arise from previous analysis in this article, but one requires special elaboration. In attending regional development discussions pertaining to rural society, I have heard time and again the view that we must share common purpose to respond effectively to the forces for change. This attitude is completely at odds with the tenor of the age into which many rural communities are stumbling. In the modern rapidly evolving world, the greatest advances are being made

Table 2. Towards Future-Oriented Community Cultures: An Action Research Agenda

\begin{tabular}{|l|}
\multicolumn{1}{c|}{ How can researchers and strategists: } \\
\hline 1. Dramatically promote awareness of global scientific \& technological advances? \\
2. Enhance local / regional endogenous research and development? \\
3. Efficiently and effectively translate (1) and (2) into a stream of ideas for innovative, lower cost and \\
better quality products and services? \\
4. Harness those ideas entrepreneurially for production of local goods and services for regional and even \\
global markets? \\
6. Lreate greater risk awareness and acceptance among local businesses and communities alike? \\
7. Engineer a large and steady flow of local / regional venture capital? \\
8. Educate rural community members in the necessary skills to enable all of the above, and especially \\
the increasingly important qualities of imagination and creativity which Brynjolfsson and McAfee see \\
as vital for unlocking new technologies? \\
9. Evaluate and quantify the public and private infrastructure necessary to promote these research \\
10. Prioritize competing projects to maximize pay-offs from alternative combinations of options, given \\
inevitable limitations in the supply of infrastructure capital? \\
11. Decide which should be the lead agencies in these tasks and whether we have enough quality \\
13. leaders? \\
contests of ideas crucial to the creation of future-oriented communities?
\end{tabular}


by the contest of ideas or the decisions of forceful and often isolated individuals uninterested in forming coalitions of interests. Deference to others is rarely part of innovative agendas. Both Florida (2004) and Jacobs (1961) famously extol such notions in urban contexts.

What does matter is that as many elements as possible of rural society - whether businesses, bureaucracy, civic leaders, social institutions or private individuals - reorient to the future and develop skills, attitudes and behaviors necessary to propel society ever faster forward. Consider also this point. The environmental and geographical heterogeneity of rural space is so great that the strategies created are likely to differ from one place to another! This suggests another element in the research agenda: action research to document and disseminate information about the reasons for success or failure of different strategies or approaches adopted by particular places. This takes us back to Montaigne. In rapidly changing societies, experience is a priceless asset. The bars, clubs, cafes and restaurants of Castro Street in Mountain View in the heart of Silicon Valley are the factories for disseminating experience. In the vastness of rural Australia we need other means to achieve the same outcome.

Although my arguments have been developed in an Australian context, they seem likely to hold sway over much of the developed and developing world. The scenarios sketched by Brynjolfsson and McAfee (2014), Brockman, and Pentland (2014) and Hammersley (2012) point to an acceleration in technological achievements in what Brynjolfsson and McAfee term the second machine age, especially via the blending, fusion and integration of technologies. Their adverse impact on rural and regional economies everywhere is likely to be extreme, suggesting an urgent need to revise our conventional approaches to local development. On reflection, Australia's small and medium enterprises might be better placed than most because that nation's economy is one of the world's most market oriented and therefore focused on self-survival.

\section{References}

Argent N. M., Tonts M., Jones R., Holmes J., 2013, A creativity-led rural renaissance? Amenity led migration, the creative turn and the uneven development of rural Australia, Applied Geography, 44, pp. 88-98.

Brockman J., 2014, What Should We Be Worried About? Real scenarios that keep scientists up at night, New York, Harper Collins.

Brynjolfsson E., McAfee A., 2014, The Second Machine Age: work, progress and prosperity in a time of brilliant technologies, New York, Norton.

Deloitte, 2014, Positioning for prosperity? Catching the next wave, Building the Lucky Country: Business imperatives for a prosperous Australia, Report \#3, Sydney, Deloitte Touche Tohmatsu Limited. [see www.buildingtheluckycountry.com.au]

Florida R., 2004, Cities and the Creative Class, New York, Routledge.

Hammersley B., 2012, 64 Things You Need to Know Now for Then, Sydney, Hodder.

Jacobs J., 1961, The Death and Life of Great American Cities, New York, Random House.

Lem S., 2013, Summa Technologiae, Minneapolis, University of Minnesota Press. [a translation of the original 1964 text]

Montaigne M. de, 1580, Essais, Bordeaux, Simon Millanges. 
Pentland A., 2014, Social Physics: How Good Ideas Spread - The Lessons from a New Science, Penguin Press, New York.

Prechter R. Jr., 2003, Socionomics: The Science of History and Social Prediction, Gainesville, GA, New Classics Library.

Productivity Commission, 2005, Trends in Australian Agriculture, Research Paper, Canberra.

Regional Australia Institute, 2012, Tapping the Growth Potential of Regions for National Success, Canberra, RAI Policy Briefing. Sourced at: http://www.regionalaustralia.org.au/wp-content/ uploads/2013/06/RAI-OECD-Regional-Policy-Briefing.pdf.

Savage M., Devine F., Cunningham N., Taylor M., Li Y., Hjellbrekke J., Le Roux B., Friedman S., Miles A., 2013, A New Model of Social Class: findings from the BBC's Great British class survey experiment, Sociology, 47 (2), pp. 219-250.

Sorensen A. D., 2000, Regional Development: Some Issues for Policy Makers, Research Paper, 26, 1999-2000, Department of the Parliamentary Library, Canberra.

Sorensen A. D., 2002, Regional Economic Governance: States, Markets and DIY, [in] Bell S. (ed), Economic Governance and Institutional Dynamics, Oxford, Oxford University Press, pp. 262-285.

Sorensen A. D., 2009a, Creativity in Rural Development: an Australian response to Florida (or a view from the fringe), International Journal of Foresight and Innovation Policy, 5, (1/2/3), pp. 24-43.

Sorensen A. D., 2009b, Local development under uncertainty; Australia's rural perspective, Rural Studies, 20, pp. 7-26.

Sorensen A. D., 2009c, Australian Rural Development: multiple problems, bespoke solutions, the abdication of central governments and the ghost of Friedrich Nietzsche, [in:] Frutos L. M., Climent E., Ruiz E., Bicalho A. M., Laurens L. (eds), New Ruralities and Sustainable Use of Territory, Zaragoza, IGU Commission on the Sustainable Development of Rural Systems, pp. 257-268.

Sorensen A. D., 2010, The Psychology of regional Development, Australasian Journal of Regional Studies, 16 (1), pp. 85-98.

Sorensen A. D., 2011a, Australian Agricultural R\&D and Innovation Systems, International Journal of Foresight and Innovation Policy, 7 (1, 2, 3), pp. 192-211.

Sorensen A. D., 2011b, Quantum Dreaming: the relevance of quantum mechanics to regional science, Australasian Journal of Regional Studies, 17 (1), pp. 81-99.

Sorensen A. D., Epps., 2005, The Idea of Stable Adaptation and its Origins, [in:] Mather A. (ed.), Land Use and Rural Sustainability, International Geographical Union Commissions on Land Use/ Cover Change and the Sustainability of Rural Systems, University of Aberdeen, pp. 1-10.

Sorensen A. D., Marshall N., Dollery B., 2007, Changing Governance of Australian Regional Development: Systems and Effectiveness, Space and Polity, 11 (3), pp. 297-315.

Stephenson N., Brin D., Egan G., Powers R., Robson J., Watts P., Aldiss B. W., Ridbom C., McAuley P., Kress N., Steele A., McDonald I., Fulda N., Goonan K. A., 2013, Twelve Tomorrows, Cambridge, Mass., Technology Review, Inc.

Storey K., 2001, Fly-in/Fly-out and Fly-over: Mining and regional development in Western Australia, Australian Geographer 32 (2), pp. 133-148.

Taleb N., 2007, The Black Swan: The Impact of the Highly Improbable, New York, Random House.

Taleb N., 2012, Antifragile: Things That Gain From Disorder, London, Penguin.

World Bank, 2011, Multipolarity: The New Global Economy, The International Bank for Reconstruction and Development, Washington D. C. 